\title{
Una aproximación a la integración del servicio religioso en la Corte de Fernando el Católico: su papel dentro y fuera del séquito regio*
}

\section{An approximation to the integration of religious service in the court of Ferdinand the Catholic: its role within and outside the royal entourage}

\section{Germán GAMERO IGEA}

Universidad de Valladolid

\begin{abstract}
Considered one of the king's private departments, Ferdinand II's royal chapel, constructed in the Aragonese tradition, shows an important connection between the courtly sphere and political life during his reign. During this period, the royal clergy was especially active both inside and outside the court. In this article we will try to emphasize how the royal clergy took on the different changes of Ferdinand's government and how the king's clerics established their ties inside and outside the royal entourage.
\end{abstract}

Keywords: Ferdinand II of Aragon, Royal Chapel, Corte, Reform, Inquisition.
Resumen: Considerado como uno de los departamentos privados de soberano, la Capilla de Fernando II muestra una importante conexión con la esfera cortesana y la vida política durante el reinado. En el presente estudio se mostrarán algunos de los rasgos que definieron el servicio religioso a lo largo del reinado así como algunos de sus principales artífices y colaboradores. La dimensión institucional, la religiosidad, la conexión con las elites regnícolas así como su diferencial participación en la vida política (y religiosa) de los reinos serán nuestros hilos rectores.

Palabras clave: Fernando II de Aragón, Capilla, Corte, Reforma, Inquisición.

\section{INTRODUCCIÓN}

La imbricación entre los poderes políticos y religiosos, omnipresentes en las sociedades pre-modernas europeas, alcanza algunos de sus picos recurrentes en los impulsos reformistas. La herencia del Medievo ofrece a finales del siglo XV un amplio bagaje de situaciones y estrategias que evidencian la conexión entre polí-

* El presente trabajo se ha realizado en el marco del Proyecto de Investigación «Islam medieval en Castilla y León: realidades, restos y recursos patrimoniales (ss. XIII-XVI)» (VA058U14) < http:// albergueweb.uva.es/islam-medieval-castilla-leon/>. 
tica y reforma, y así han sido puestos en valor por diferentes especialistas ${ }^{1}$. Para el gobierno de los Reyes Católicos expresiones como el máximo religioso o la reforma antes de la Reforma han sido algunas de las formulaciones teóricas con más éxito en la historiografía para conceptualizar y actualizar dicho problema ${ }^{2}$. Tanto es así que podríamos considerarlos como algunos de los epítomes más característicos de los cambios producidos durante su reinado. Es más, podríamos considerarlos como algunos de los rasgos más modernos de su reinado. Bajo su paraguas no sólo se reproduce la pugna entre franciscanos y dominicos, claustrales y observantes, o rigoristas y anti-rigoristas. Se engloba igualmente el recurso, tan característico de siglos posteriores, de encumbrar a una orden típicamente hispana, la jerónima en este caso, como pilar en las políticas del Estado. El ejemplo más representativo es el papel de Hernando de Talavera en la política de su tiempo. No obstante la relación entre la Orden y la Monarquía (y las élites, en su conjunto) jalonó la vida política y ceremonial de la Corte de los Reyes Católicos ${ }^{3}$. En esta misma dirección, mucho más relevante resulta la defensa de las líneas directrices del Patronato Regio y, en general, la responsabilidad del poder político sobre las conciencias de sus súbditos. La sintonía entre los grupos de poder fernandino e isabelino parece que fue firme en este ámbito y, con sus matices, también resultó eficaz. Se trata de uno de los pilares más estables del señorío a una y, si eso supone una fortaleza en la concreción del programa, supone también ciertas peculiaridades en la manera en como se vivió dentro del núcleo político/cortesano, también en el grupo religioso. Observaremos a lo largo de estas páginas cómo es posible percibir una progresiva vinculación de la cuestión religiosa con la Capilla y el aparato cortesano en su conjunto. Posiblemente podamos achacar esta evolución a la propia madurez de las políticas aplicadas durante el reinado. Pero también es importante ponderar el peso que la cuestión religiosa tuvo para la articulación de

1 Entre los numerosos estudios sobre el tema puede señalarse la obra colectiva Isabel BECEIRO PITA, Poder, piedad y devoción: Castilla y su entorno (ss. XII-XV), Madrid, 2014, así como algunas de las últimas publicaciones de Guillermo NIEVA OCAMPO, De la colaboración a la oposición: los frailes dominicos y la realeza castellana (1370-1474), en Erasmo. Revista de historia Bajomedieval y Moderna, 3 (2016), pp. 89-99; Juan Antonio PRIETO SAYAGUÉs, El acercamiento de la monarquía castellana a la Orden de los Predicadores durante el reinado de fuan II de Castilla (1406-1454), en En la España Medieval, 39 (2016), pp. 197-224.

2 Para un estudio de la política religiosa de los Reyes Católicos véase, Luis SuÁrEz FERnáNDEZ, Los Reyes Católicos: la expansión de la fe, Madrid, 1990; ID., El máximo religioso, en Enrique SARASA (coord.), Fernando II de Aragón, el Rey Católico, Zaragoza, 1996, pp.47-60.; Tarsicio DE AzCONA, Isabel la Católica. Estudio crítico de su vida y su reinado, Madrid, 1993.

3 Sobre la biografía del jerónimo véase Francisco Javier MARTínEZ Medina, Fray Hernando de Talavera: Primer arzobispo de Granada, hombre de Iglesia, Estado y Letras, Granada, 2011. 
los servidores cortesanos (los conocidos como partidos) cuando ese proyecto pasó a ser debatido, pudiendo observar la influencia de las sucesivas crisis dinásticas y en especial la muerte de Isabel I.

La idea no es radicalmente novedosa. Así pues, si bien el liderazgo de los soberanos, en cuanto tales, ha sido tenido en cuenta por la historiografía, el carácter vehicular del problema religioso ha llevado a los estudiosos a proponer un punto de vista más totalizador. Se han estudiado las herramientas que hicieron posible el despliegue de la política religiosa en tiempos de los Reyes Católicos ${ }^{4}$. Se ha debatido y puesto especial énfasis en la ideología de dichas innovaciones ${ }^{5}$. Incluso nos son relativamente bien conocidos los grupos de poder, tanto masculinos como femeninos, que apoyaron la tarea de la reina ${ }^{6}$. Fernando II y su partido han recibido también su oportuna atención, en especial tras el ascenso al poder de Juana I y su marido Felipe 7 .Gracias a esos trabajos hoy en día conocemos algunos de sus rasgos definitorios y en especial les debemos su apelativo de rigorista, por oposición a las ideas flamencas y de determinados sectores de las élites castellanas contrarias a esta política que alzan su voz con el debilitamiento y muerte de la reina. En esta ocasión nos detendremos en el análisis de la Capilla de Fernando II

4 Sobre algunos de los mecanismos más destacados véase m John H. ELIOTT, La España Imperial (1469-1716), Barcelona, 1965; las ponencias editadas en Julio VALEDÓN BARUQUE (ed.), Isabel la Católica y la Política, Valladolid, 2001 e ID., Sociedad y economía en tempos de Isabel la Católica, Valladolid, 2001; así como la obra de Álvaro FERNÁNDEZ DE CóRdOVa MIRALLES, Alejandro VI y los Reyes Católicos: relaciones político-eclesiásticas (1492-1503), Roma (Dissertationes. Series Theologica, t. 16) 2005.

5 Especialmente en la cuestión de la expulsión de los judíos, la conversión de las minorías y el establecimiento de la inquisición son referencia del debate, todavía abierto, Benizón NETANYAHU, Los orígenes de la Inquisición en la España del siglo XV. Barcelona, 1999; Luis SUÁREZ FERNÁNDEZ, Claves históricas del reinado de Fernando e Isabel, Madrid, 1998; Henry KAMEN, Fernando el Católico, el absolutismo y la Inquisición, en Aurora EGIDO y Enrique LAPLANA (eds.), La imagen de Fernando el Católico en la Historia, la Literatura y el Arte, Zaragoza, 2015, pp. 15-28.

6 A este respecto Antonio DE LA TORRE Y DEL Cerro, La Casa de Isabel la Católica, Madrid, 1954; Álvaro FERNÁNDEZ DE CóRDOVA MIRALles, La Corte de Isabel I. Ritos y ceremonias de una reina (1474-1504), Madrid, 2002; María del Cristo GonZÁlez MARrero, La casa de Isabel la Católica. Espacios domésticos y vida cotidiana, Ávila, Institución Gran Duque de Alba - Diputación Provincial de Ávila, 2005, ID., Las mujeres de la Casa de Isabel la Católica, en José MARTíNEZ MiLLÁN y María Paula MARÇAL LourenÇO, Las relaciones discretas entre las Monarquías Hispana y Portuguesa: Las Casas de las Reinas (ss. XV-XIX), Madrid, vol. 2, pp. 841-886.

7 Sobre estas consideraciones véase José MarTínez MiLlán y Teresa SánCHEZ RiviLla, El Consejo de Inquisición (1483-1700), en Hispania Sacra, 36/73 (1984), pp. 71-193; José MARTíNEZ MILLÁN, Las elites de poder durante el reinado de Carlos $V$ a través de los miembros del Consejo de Inquisición (1516-1558), en Hispania, 48/168 (1988), pp. 103-168; ID., La evolución de la Corte castellana durante la segunda regencia de Fernando (1507-1516), en José MARTínEZ MILLÁN (coord.), La Corte de Carlos V, Madrid, vol. 1, pp. 103-113. 
desde una perspectiva cronológica más amplia. Observando el entorno cortesano y sus cambios en el trascurso de los largos años de su reinado nos proponemos mostrar el papel de la Capilla en el sistema cortesano del momento. Sin duda se destacará su carácter de espacio de religiosidad específico del monarca. Pero nuestras reflexiones se detendrán especialmente en la Capilla como un ámbito de reconocido abastecimiento de grandes colaboradores regios, como parte del entramado del partido fernandino, aspecto en absoluto desconocido para los soberanos de su entorno ${ }^{8}$. Trabajos de gran calado nos animan a plantear nuestro enfoque hacia la vertiente humana de aquel grupo de religiosos, ponderado su posición en el seno de los colaboradores fernandinos y dejando de lado otras vertientes, como la material y la ceremonial, subrayadas por Fleckenstein. Sin duda resultan esenciales para comprender en su conjunto el funcionamiento del órgano religioso de la Corte, pero son imposibles de abordar en un estudio de estas características ${ }^{9}$. Este trabajo, por tanto, se articulará desde una doble visión fraccionada a su vez en cuatro. En primer lugar la definición de las condiciones internas de la Capilla en el juego cortesano (sus contornos y sus funciones) y, por otro lado, las condiciones extrínsecas al propio órgano religioso que afectaron a su funcionamiento (su presencia en las redes internas en la Corte y su capacidad para proyectarse hacia el exterior). Todo ello desde una perspectiva diacrónica a lo largo del reinado fernandino.

Para ello deben tenerse en cuenta las especiales consideraciones que matizan y contextualizan el gobierno del Rey Católico. En especial puede destacarse el carácter combativo del monarca, ya sea en la administración castellana, o con

8 Son destacables algunos colaboradores fernandinos que no trabajaremos en esta ocasión recogidos en Álvaro FERNÁNDEZ DE CóRdOVA MiRALles, Imagen de los Reyes Católicos en la Roma pontificia, en En la España Medieval, 28 (2005), pp. 259-354; ID., Diplomáticos y letrados en Roma al servicio de los Reyes Católicos: Francesco Vitale di Noya, Fuan Ruiz de Medina y Francisco de Rojas, en Dicenda: Cuadernos de filología hispánica, 32 (2014), pp. 113-154. Para reinados anteriores véase Óscar VillarRoel GONZÁLEZ, Capilla y capellanes reales al servicio del rey en Castilla: la evolución en época de Juan II (1406-1454), en En la España Medieval, 31 (2008), pp. 309-356; David NoGALES RINCÓN, La representación religiosa de la monarquía castellano-leonesa: la capilla real (1252-1504), Tesis doctoral inédita, defendida en la Universidad Complutense de Madrid, 2009; Óscar VILLARroeL GONZÁLEZ, Eclesiásticos en la diplomacia castellana en el siglo XV, en Anuario de Estudios Medievales, 40 (2010), pp. 791-819.

9 Josef FleCKEnSteIn, Die Hofkapelle der Deutschen Könige, Stuttgart, 1959. Para la cultura material véase David Nogales RINCón, La Capilla del Rey Católico: orfebrería religiosa de Fernando II de Aragón en 1542, en Anuario del Departamento de Historia y Teoría del Arte, 19 (2007), pp. 51 66. Sobre el aspecto ceremonial y su concreción en la Corte José Manuel NIETO SORIA, Ceremonias de la realeza: propaganda y legitimación en la Castilla Trastámara, Madrid, Nerea, 1993; Álvaro FERNÁNDEZ DE CóRDOVA MiRALles, La Corte de Isabel I... [ver n. 6]. 
los poderes eclesiásticos (tanto dentro como fuera de las fronteras de sus reinos). Nos referimos a la pugna entre el soberano y el clero de sus reinos, en especial el barcelonés, por su implicación en el programa de gobierno fernandino (los redreç $)^{10}$. Pero también valoramos las tensas relaciones del rey con el papado, ya sea en calidad de príncipes italianos o de su carácter de príncipe hispano, recordando por tanto su defensa del patronato regio. Desde todas estas consideraciones nos adentraremos en un análisis que procurará abordar la relación poliédrica del último trastámara con el clero de sus reinos así como la participación de este en los afanes políticos de Fernando II.

\section{RASGOS CARACTERÍSTICOS DE LA CAPILla DEL REY CATÓLICO}

Tanto por la liturgia regia como por la fuerte conexión entre el clero y la realeza, la dimensión religiosa es uno de los aspectos que caracterizan al poder regio medieval. Desde la cuna carolingia, la actividad de los clérigos letrados fue conociendo diferentes niveles de presencia en el entorno regio. No resulta novedoso, por tanto, subrayar el hecho de que gran parte de los colaboradores de los monarcas medievales procedieron del estamento clerical y que su influencia se dejó sentir en la justificación e impulso de las principales gestas de los soberanos ${ }^{11}$. Su presencia en la cancillería hizo valer sus derechos en la compleja pugna por el establecimiento del poderío real absoluto a la vez que establecía los mecanismos para el afianzamiento de su memoria ${ }^{12}$. Otros volcaron su experiencia en la administración del propio peculio regio. Por último una pléyade de ellos jalonó la política ceremonial de la Monarquía desde la unción o coronación (en aquellos casos aplicables) hasta las exequias reales, pasando por las múltiples ceremonias de conmemoración de la Monarquía ya fuese en el seno de la Corte o a lo largo del reino ${ }^{13}$.

10 Sobre los conflictos con el clero barcelonés, y en menor medida el valenciano, véase, Jaume VICENS VIVES, Ferran II y la ciutat de Barcelona, 1479-1516, Barcelona, 1936; Ernest BELENGUER CEBriá, Fernando el Católico y la ciudad de Valencia, Valencia, 2012.

11 Un recorrido para todo el periodo medieval excedería los objetivos de este trabajo, sin embargo para el periodo bajomedieval resulta inexcusable la referencia a José Manuel NIETO SORIA, Iglesia y génesis del Estado moderno en Castilla (1369-1480), Madrid, 1993.

12 Un análisis del concepto del poderío real absoluto en José Manuel NiETO SORIA, El poderío real absoluto de Olmedo (1445) a Ocaña (1469): La monarquía como conflicto, en En la España medieval, 21 (1998), pp. 159-228.

13 José Manuel NiETO SORIA, Ceremonias de la realeza: propaganda y legitimación en la Castilla Trastámara, Madrid, 1993. 
Todo ello propició la creación de un lenguaje basado en la metáfora religiosa encargado no sólo de ensalzar a la Monarquía sino también a los propios servidores regios. El más evidente es el de la «Corte celestial», pero incluso las imágenes religiosas sirven a los pensadores medievales para justificar o proyectar el sistema cortesano. Para el reinado de los Reyes Católicos resulta sugerente, por ejemplo, la afirmación del anónimo autor de la crónica incompleta que ensalza la figura de los cronistas a la posición de evangelistas de lo temporal ${ }^{14}$. Junto a ello habría que incorporar, al menos, otra dimensión al servicio regio que tendrá una gran importancia en nuestro trabajo: la carga simbólica de la tradición a la hora de configurar un espacio identitario y político, defendido en diferentes ocasiones por la sociedad política bajomedieval. Es por ello por lo que detendremos nuestro análisis en primer lugar en el perfil institucional, en los cambios y permanencias observables en el entorno del Rey Católico, pues suponen la base para el comportamiento de la Corte en su conjunto y también de la Capilla.

\section{II.1. La evolución institucional}

Según la visión comparada de Rita Costa Gomes, el desarrollo de las capillas regias ibéricas se caracteriza, en la Baja Edad Media, por la redacción de respectivas ordenanzas ${ }^{15}$. Tomando la herencia del reinado de Alfonso X, sin duda estos textos proliferaron tanto en Castilla como en Portugal durante la primera mitad del siglo $\mathrm{XV}^{16}$. En nuestro caso, el punto de inflexión radica en un hecho histórico semejante aunque en una cronología anterior al último siglo medieval. Nos referimos a la redacción de las Ordinacions de la Casa Real aragonesa, que no perdieron su vigencia durante el reinado de Fernando II. Es cierto que el esquema propuesto por el Ceremonioso sufrió numerosas modificaciones, incluso en del reinado de Pedro IV. Sin embargo podemos observar cómo el Rey Católico mantuvo muchos de sus aspectos formales, en especial en los dos ámbitos en los que el clero disfrutaba de una importante presencia: la Cancillería y la Capilla ${ }^{17}$.

14 Crónica incompleta de los Reyes Católicos (1469-1476), ed. por Julio Puyol, Madrid, 1934, p. 90.

15 Rita Costa Gomes, The Royal Chapel in Iberia: Models, Contacts, and Influences, en The Medieval History fournal, 12/1 (2009), pp. 77-111.

16 Para el caso castellano véase José Manuel NiETO SORIA, La capilla real castellano-leonesa en el siglo XV: constituciones, nombramientos y quitaciones, en Archivos Leoneses: revista de estudios y documentación de los Reinos Hispano-Occidentales, 85-86 (1989), pp. 7-54.

17 Alexandra BEAUCHAMP, La composition de la Casa $i$ Cort du roi d'Aragon. Normes et pratiques au début du règne de Pierre le Cérémonieux, en Erasmo. Revista de Historia Bajomedieval y Moderna, 1 
Así, sabemos que para la Corona de Aragón el canciller debía ser un arzobispo o un obispo doctor en leyes, sin que el cargo se vinculase con una dignidad concreta como había ocurrido en Castilla. Esa misma dinámica se mantuvo en el reinado de Fernando II con importantes repercusiones si nos fijamos en quién detentó ese oficio ${ }^{18}$. Entre todos sus cancilleres destaca la figura del Cardenal Margarit, posiblemente el que más atención ha recibido por parte de la historiografía ${ }^{19}$. Obispo de Elna, su papel en la política interior y exterior de Juan II y Fernando el Católico hizo que se mantuviera en una posición privilegiada, incluso ante el constante absentismo que sus funciones reclamaban. Sin embargo también merecen ser destacados otros personajes relevantes que ocuparon dicho cargo, aunque fuese por un tiempo más reducido. Todos ellos tuvieron importantes implicaciones en el servicio cortesano. Es el caso de Fadrique de Urriés, quien destaca por ocupar entre 1466 y 1469 los cargos de canciller y capellán mayor, convirtiéndose por tanto en rector de la vida de los clérigos de la Corte del joven infante ${ }^{20}$. Pero mención especial merece también Antonio de Espés, obispo de Huesca, por formar parte de la densa familia realista, al servicio de sucesivos reyes aragoneses, pero especialmente presentes en los séquitos de los últimos trastámaras ${ }^{21}$.

Tras estos importantes consejeros la figura de los clérigos de la Corte comienza a agotarse en la Cancillería. Así por ejemplo las propias Ordinacions establecían que el vicecanciller no debía de estar ordenado para poder hacer lo que

(2014), pp. 21-42. Para el caso de Fernando el Católico hemos destacado la importancia de las modificaciones realizadas en el entorno regio en Germán GAMERO IGEA, Ordenar la Corte y gobernar los territorios. Dinámicas y estructuras de poder en el entorno de Fernando el Católico, en Guillermo NiEVA, Rubén GONZÁLEZ y Andrea M. NAVARRo (coords.), El príncipe, la Corte y sus reinos, Tucumán, 2016, pp. 139-166. Sobre las modificaciones de la Capilla aragonesa en tiempos de los trastámaras pueden destacarse María Isabel OsTOLAZA EliZONDO, D. Fuan de Aragón y Navarra, un verdadero príncipe Trastámara, en Aragón en la Edad Media, 16 (2000), pp. 591-610; Roxane CHILÁ, Une cour à l'épreuve de la conquête: la société curiale et Naples, capitale d'Alphonse le Magnanime (1416-1458), Tesis doctoral inédita defendida en la Universidad de Montpelier, 2014; Germán GAMERO IGEA, Epílogo de un reinado y desmembramiento de una Corte: servidores de fuan II de Aragón a su muerte, en Medievalismo, 26 (2016), pp. 109-133.

18 Pascual Savall y Dronda y Santiago Penen y Debesa, Fueros, observancias y actos de Corte del reino de Aragón, Zaragoza, Francisco Castro y Bosque, 1866, p. 493.

19 Puede destacarse en este sentido las contribuciones recogidas en Mariàngela Vilallonga, Eulàlia Miralles y David Prats (eds.), El Cardenal Margarit i l'Europa quatrecentista, Girona, 2008.

20 Sus primeros registros pueden verse en BARCELONA. ARCHIVO DE LA CORONA DE ARAGÓN [=ACA]. REAL PATRIMONIO [=RP]. MAESTRE RACIONAL [=MR], vol. 939, fol. 71r.

21 Sobre la evolución de esta familia en el séquito del príncipe véase Germán GAMERO IGEA, Ordenar la Corte y gobernar los territorios... [ver n. 17]. 
por ventura no podría el canciller siendo arzobispo u obispo u otro prelado o clérigo ${ }^{22}$, esto es, despachar sentencias criminales. Dicha recomendación la cumplen a la perfección oficiales fernandinos como Alonso de la Cavallería, Tomás Malferit, Juan Pagés o Juan Monet. Pero tampoco encontramos en el séquito del monarca el oficio del enderezador de conciencia del consejo (cargo distinto al de confesor regio), para el que se requiere ser obispo, prelado, maestro en teología o doctor en derechos. Incluso dentro de los oidores resulta complicado determinar en muchas ocasiones cuál debió ser el clérigo que, junto con el oficial perteneciente al estamento de los caballeros, se encargase de despachar las suplicaciones que llegasen hasta el tribunal.

Por tanto al hablar de la clerecía integrante del entorno de Fernando II debemos detenernos especialmente en la Capilla. Ya en dicho departamento puede observarse una combinación entre la tradición aragonesa y la innovación (especialmente procedente de Castilla y de poderoso séquito de su primera mujer) muy sugerente para nuestra reflexión, más general, de su imbricación en la política y en la vida cortesana. Institucionalmente, y a grandes rasgos, el entorno religioso siguió organizado bajo la autoridad del abad de Santes Creus, su capellán mayor, y el de Poblet, su limosnero. Ambos seguirán siendo los pilares que articularon las relaciones de poder en el seno del clero palatino, si bien sólo en teoría. Como veremos, en ambos cargos lo que puede observarse es un progresivo alejamiento de las directrices de las Ordinacions, proceso que comparten con otros ambientes del séquito regio ${ }^{23}$.

En el caso del capellán mayor, ya hemos mencionado la figura de Fadrique de Urriés y las altas cotas que llegó a asumir en la infancia fernandina. No sería el único capellán mayor antes de llegar al trono. También Pedro de Embún ejerció dicho cargo entre 1467 y 1474, con un perfil más bajo que el anterior, al menos por los datos de que disponemos en la actualidad ${ }^{24}$. Sin embargo con la llegada al trono de Fernando II observamos cómo este oficial vuelve a ponerse en valor, como se observa en la figura de don Pedro de Mendoza. Este oficial fue nombrado abad de Santas Creus el 14 de septiembre de 1479 y detentaría dicho cargo hasta $1519^{25}$. Su preeminencia en la reforma de la abadía y su participación en la vida política catalana, nos es relativamente bien conocida. Sin embargo para

22 Pascual Savall y Dronda y Santiago Penen y Debesa, Fueros... [ver. n. 18] p. 404.

23 Germán GAMERo IGEA, Ordenar la Corte y gobernar los territorios [ver n. 17].

24 El nombramiento de Embún se encuentra en ACA.RP.MR. vol. 939, fol. 55r; ibid., vol. 954, fol. 23 r.

25 Roser Salicrú i Lluc, Pedro de Mendoza. Abad de Santes Creus, en Josep María Solé i Sabaté, História de la Generalitat de Catalunya i del seus presidents (1359-1518), Barcelona, 2003, pp. 247-252. 
nuestro estudio resulta interesante poner en conexión estos datos con la merma de influencia cortesana del capellán mayor aragonés que personifica su mandato.

Es cierto que enviaría a un representante suyo a la Corte, Bernat Cardona (al menos entre 1479 y 1482) ${ }^{26}$. Sin embargo poco a poco la autoridad sobre los capellanes fue recayendo de manera más directa en quien sería el gran acompañante de Fernando II: Alonso Cortés, su sacristán mayor (cargo externo a la tradición aragonesa y posiblemente proveniente de Navarra o Castilla). El poder de este oficial fue tal que en alguna ocasión llegará a ser denominado como lugarteniente del capellán mayor, seguramente por realizar esas mismas funciones. No obstante esa denominación resulta, al mensos institucionalmente, errónea, pues dicho cargo debía pertenecer a un monje de Santes Creus ${ }^{27}$. En cualquier caso la evolución del cargo de capellán mayor culminaría para el reinado de Fernando II con la conquista de Nápoles. Tras ese momento puede observarse una última pérdida de representatividad del abad de Santes Creus al aparecer la figura de un capellán mayor de la Corona de Aragón y otra del reino de Nápoles. Dicha figura recaería, al menos, en Juan María Poderico, capellán mayor de Nápoles desde el uno de octubre de $1506^{28}$. Tanto la persona en la que recae como la fecha en la que aparece dicho cargo resultan representativas. Hay que tener en cuenta que es la fecha en torno a la cual aparecen una serie de oficiales de origen napolitano que formarían una verdadera casa fernandina en Nápoles. El ejemplo más evidente de este proceso es el nombramiento del cazador mayor, Alejandro Gostança, governador en les coses tocans a la casa real de sa alteza en lo dit realme de Nápoles ${ }^{29}$. Tras él podrían destacarse igualmente a los integrantes del Sacro Consejo y la Cámara de la Somaria, que se incorporarían a la Corte virreinal napolitana en un ejemplo de respeto a la forma organizativa tradicional de los reinos ${ }^{30}$.

Una panorámica semejante (si bien no idéntica) puede trazarse a la hora de analizar la limosnería regia. En este caso, uno de los primeros matices que sorprenden al historiador es el hecho de que la autoridad del abad de Poblet puede sentirse ya desde la infancia de Fernando II. Recordemos que no había sido el caso del abad de Santes Creus y que no era una directriz establecida en las $\mathrm{Or}$ -

26 ACA.RP.MR. vol. 920, fol. 3v; ibid., vol. 945, fol. 171v.

27 La denominación no es constante, sino esporádica, apareciendo en ciertos albalaes de 1506 (ACA. PR.MR. vols. Serie B; vol. 29, fol. 862v), 1507 (ibid., fol. 867v) y 1508 (ibid., fol. 871r).

28 ACA.RP.MR. vol. 920, fol. 220r.

29 Ibid., fol. 189 r.

30 Sobre los cargos de la Corte virreinal napolitana en 1510 véase MADRID, REAL ACADEMIA DE LA HisTORIA, Colección Salazar y Castro, vol. A-13, fols. 56-85. 
dinacions. En este caso bien es verdad que no encontramos el nombramiento del abad como limosnero del príncipe, pero sí se observa el envío de lugartenientes a su Corte. Tal vez dicha situación pueda explicarse por la relevancia ostentada por el abad en el consejo de la reina Juana y en las difíciles negociaciones con el principado en los prolegómenos de la guerra civil. Sea como fuere el cargo de limosnero (y de sus lugartenientes) siguió dependiendo del Abad de Poblet durante toda la etapa de Fernando como príncipe. Ejemplo de ello es el nombramiento de Pere Gilbert en 1466 y (Juan) Payo Cuello en 1479 como sus lugartenientes $^{31}$. Dicha colaboración debió resultar fructífera pues muy poco después, a partir de 1480, este último personaje pasó a la dirección del cenobio. Como contrapartida, otro de los grandes colaboradores del monasterio, Juan Ruiz, que había sido hombre de confianza de Juan II, comenzó a perder su ascendencia sobre la limosnería regia. Esta presencia del abad de Poblet se seguiría sintiendo a lo largo del reinado del Rey Católico, y aunque no podamos confirmar la presencia de este oficial en el entorno del rey, al menos la documentación muestra su influjo con la confirmación un lugarteniente del abad en 28 de octubre de 1506, Antonio Riquer ${ }^{32}$.

Sin embargo de nuevo la distancia de la Corte hizo mella en la posición del titular del oficio, y en realidad las funciones de la limosnería fueron asumidas por personajes más cercanos al rey, en concreto dos mozos de la limosnería que estarían relacionados con el clan de los Cortés (Sancho y Martín ${ }^{33}$ ). Por otro lado, y en contraste con lo que ocurría para el caso del capellán mayor napolitano, también es posible observar un importante cambio en la limosnería regia en relación a Castilla, pero en este caso con un matiz bien distinto. Así, fruto de la colaboración castellana, especialmente intensa en los asuntos pecuniarios, puede observarse la aparición de un limosnero del rey en la Corona occidental. Se trata de Pedro de Alcaraz, prior de Aracena, vinculado con una importante familia de colaboradores fernandinos y del que la documentación nos da muestra de su actividad al menos entre 1470 y 1496 sin que sepamos si otro capellán tomó su relevo $^{34}$. Sin embargo con ello no debe hacerse una analogía con el caso partenopeo. No consideramos que se trate de un desdoblamiento de las tareas religiosas, en

31 ACA.RP.MR. vol. 920, fols. $55 \mathrm{v}$ y $3 \mathrm{v}$, respectivamente.

2 Ibid., vol. 844, fol. $151 \mathrm{v}$.

33 Ibid., vols. Serie B; vol. 29, fol. 845r y fol. 828v respectivamente.

34 Su asiento aparece recogido en ACA.RP.MR. vol. 939, fol. 55v. La última noticia acerca de sus servicios que poseemos se sitúa en ARCHIVO GENERAL DE SiMANCAS. REGISTRO GENERAL DEL SELLO, leg. 1495-03.doc.343. 
Castilla y Aragón. Más bien debemos hablar de un oficial directamente vinculado a la administración aragonesa (es decir, a la Escribanía de Ración en lo administrativo, al capellán mayor aragonés en lo religioso) que ejerce sus tareas en el suelo castellano, de donde es originario, especializándose en un ámbito concreto pero no rompiendo la estructura de la Corte.

Aunque la situación de los dos puestos pueda reportarnos peculiaridades propias de cada caso, de ambos pueden extraerse algunas conclusiones comunes que nos sirvan de piedras angulares en nuestro trabajo. En primer lugar puede observarse la fuerza de las instituciones así como la conservación de los parámetros heredados de la tradición aragonesa. Con esta rigidez la Capilla del rey mantuvo unas instituciones como focos de poder que, como veremos, ejercieron sin dificultad y que hacían referencia a la autoridad que el paso del tiempo (y la propia institución monárquica, pues no hay que olvidar que se trata de panteones reales) les había atribuido. Un ejemplo de ello resulta la dimensión simbólica de dichas instituciones. Pero además hay que considerar su posición en los órganos de gobierno (especialmente catalanes, en donde se situaban los dos cenobios que Pedro IV estableció como pilares de la capilla regia) para comprender el carácter efectivo de dicho poder.

Sin embargo no todo es tradición en el séquito del Rey Católico, pues también se observa cierta maleabilidad. Un ejemplo de ello lo observamos en el nombramiento de los efectivos (en muchas ocasiones castellanos) en aquellos puestos más relevantes, pero también en el desempeño efectivo de las responsabilidades, creándose cargos novedosos, en especial el de sacristán mayor. El ascenso de la familia de Alonso Cortés nos permitirá hablar no sólo de la importancia de un servicio continuado a la hora de obtener posiciones ventajosas en el servicio regio, también de sus límites. Volveremos sobre esta cuestión, no obstante previamente deberíamos considerar otros cambios, relacionados con la función de los capellanes en el seno de la Corte, para disponer de una panorámica lo más certera posible para un trabajo de estas dimensiones.

\section{II.2. La extensión del servicio religioso}

Uno de los cambios sustanciales a la hora de valorar el servicio religioso es aquél que afecta a la dimensión y función del mismo. Para cumplir con su misión religiosa la Capilla aragonesa, y pronto su homóloga castellana, fueron adquiriendo a lo largo de los siglos bajomedievales una serie de privilegios de tipo religioso otorgados por la curia pontificia. Con ellos los capellanes pro- 
fundizaron en su tarea de cura de almas a la vez que la Capilla conseguía una organización más eficaz para dicho cometido ${ }^{35}$. El resultado de ese proceso fue la atribución de un carácter de exclusividad y especificidad al espacio religioso del monarca. Sin duda esta evolución puede explicarse como una extensión de la proximidad del monarca con la divinidad, tal y como remarcaba el pensamiento político de la época ${ }^{36}$. Reflejo de ello son algunos privilegios como el relacionado con el culto eucarístico, como supone el reconocimiento del rito cisterciense, toledano y romano en la Capilla real en $1474^{37}$. También la celebración de los oficios de la Semana Santa y en especial la construcción del monumento con sus exenciones, resultan muy reveladores. Desde una visión más vivencial destacarían por último otros aspectos que privilegian la religiosidad regia como la elección de confesor o la habilitación del mismo para perdonar pecados reservados ${ }^{38}$.

Entre esta agregación de privilegios que se fueron sucediendo a lo largo de los últimos reinados trastámaras merecen especial atención aquellos que muestran un cambio en la religiosidad cortesana (no sólo de la figura regia en exclusiva). Su expresión más definida quedaría remarcada en la reactivación de la cofradía de la Corte ${ }^{39}$. Resulta un ejemplo evidente de la influencia entre las diferentes tradiciones cortesanas (en este caso, de la aragonesa a la castellana) a la vez que muestra la evolución de la institución aragonesa. Pero por encima de todo ello para nuestro estudio nos interesa destacar las prerrogativas que se otorgaron a esta nueva cofradía cortesana, pues la mayoría de ellas están pensadas para todos los cortesanos e incluso a grupos de población que no lo son estrictamente, como sus familiares. Sólo encontramos algunas excepciones a esta extensión de los privilegios religiosos como son la sepultura en tiempo de entredicho y la recepción de los sacramentos específicamente por el capellán de la cofradía. Pero los privi-

35 Sobre algunos privilegios ya adquiridos (como por ejemplo la posibilidad de disfrutar de diferentes beneficios eclesiásticos sin tener que residir en ellos, base para la construcción del sistema de la gracia regia y del privilegio) véase Óscar VILLARROEL GONZÁLEZ, Capilla y capellanes reales... [ver n. 8].

36 Los privilegios papales al entorno de los Reyes Católicos están editados y recogidos en Bulas y breves pontificios relativos a la jurisdicción privilegiada de la Real Capilla, Madrid, 1878.

37 David Nogales RinCón, La representación religiosa de la monarquía... [ver n. 8] p. 498; Rita CosTA GOMES, The Royal Chapel in Iberia [ver n. 15]. p. 106.

38 Antonio DE LA TORRE (dir), Documentos sobre las relaciones internacionales de los Reyes Católicos, Barcelona, vol. 2, pp. 83-85.

39 Un estudio de los capítulos solicitados al papa así como de la historia de la cofradía en su conjunto en José García Oro, La Cofradía y Hospital de la Concepción de la Corte, en Estudios Marianos, XLV (1980), pp. 169-193. 
legios religiosos no se limitan a los derivados del establecimiento de la cofradía de la Corte. Esta posición intermedia del grupo cortesano respecto a los privilegios espirituales del rey y el resto del reino se desarrolla también del seno de la propia Capilla regia, cada vez más volcada hacia este colectivo. Tal es el caso de la gestión de los sacramentos. En algunos casos aparecerá la posibilidad de llevarlos a cabo dentro del entorno cortesano, como el bautizo, destacable tanto por la conversión de neófitos (véase el caso de las numerosas referencias a esclavas convertidas en el séquito de la Reina Católica) como por el bautismo de los vástagos de los cortesanos $^{40}$. Pero también puede reproducirse una relación de exclusividad como vemos en el matrimonio, para el cual el papado confiere la posibilidad de dispensa por parentesco; o en el caso de la reconciliación, la extensión del perdón para pecados reservados a las dignidades episcopales ${ }^{41}$.

De estas remodelaciones, firmemente defendidas por los soberanos, pueden destacarse al menos dos rasgos. El primero es la extensión de la noción de privilegio desde la Monarquía hacia los cortesanos y la vinculación de los miembros de la Corte con una manera propia de vivir su religiosidad. Así la dimensión religiosa del servicio cortesano se une a otras muchas que, ya reforzadas desde el reinado de Juan II, aproximan el servicio regio hacia la noción de nobleza o al menos privilegio. Tendríamos que tener en cuenta que la expansión de las prerrogativas religiosas, por medio de todos estos privilegios, se extiende a los oficios más humildes, que además también reciben la exención de impuestos directos, una jurisdicción propia, la facultad de llevar armas, o algunas cuestiones de tipo simbólico como la capacidad de llevar las insignias del rey, ya sea sobre su cuerpo en forma de librea o en sus solares de origen por medio de escudos heráldicos en sus casas y talleres ${ }^{42}$.

En segundo lugar, resulta importante destacar que esta «extensión del privilegio» desde la Monarquía a la Corte tiene su equivalente en los propios cape-

40 La bula se está fechada el 1 de julio de 1474 y se encuentra recogida en David NOGALES RINCÓN, La representación religiosa de la monarquía... [ver n. 8] p. 506.

41 La sucesión de bulas que confirman o amplían estos beneficios para el reinado de los Reyes Católicos están recogidas en Bulas y Breves Pontificios relativos a la jurisdicción privilegiada de la Real Capilla, Madrid, 1878.

42 Un ejemplo típico de estos privilegios para la época que nos ocupa es el de Gómez Cocón, vecino de Medina del campo, joyero de Felipe I quien le hace franco de impuestos (ARCHIvo General de Simancas. Escribanía Mayor de Rentas, Mercedes y Privilegios, Leg. 51. doc. 109). Una noticia sobre los beneficios concedidos por Juan II a sus servidores, y en especial el privilegio de apelar a los jueces de Corte en sus pleitos está recogida en el caso de Gonzalo de Alderete, ayudante de cámara del Rey Católico (AGS. REGISTRO GENERAL DEL SELLO. Leg. 149807, doc. 139). 
llanes. Por un lado las prerrogativas del capellán mayor se fueron expandiendo hacia el resto de cortesanos nombrándosele «rector de los fieles» de la Corte en 1477. Por otro, se le concedían facultades para implicar a los capellanes y religiosos del séquito regio: podía delegar su responsabilidad en aquellos, o designar a los confesores de los oficiales del rey ${ }^{43}$. El aumento de sus funciones, junto con el aumento del número total de cortesanos podrían ser dos claves para entender el aumento del número de clérigos en las cortes de los Reyes Católicos, pero sin duda no las únicas. El análisis prospográfico nos muestra que la Capilla del rey Fernando pudo convertirse en un receptor de miembros de diferentes dinastías de servidores cortesanos. Así lo hemos destacado para las grandes familias como los de Espés o Urriés, pero también conviene valorar dicha opción para el conjunto de la administración cortesana. Tan sólo sería necesario indicar un último aspecto que nos permita dar ese salto, que es el aumento de los efectivos en la Corte, también dentro del séquito religioso. Así, habría que recordar la preeminencia que alcanzó la Capilla de la reina Isabel I siendo, con gran seguridad, la más numerosa de su época. En el caso de Fernando II las magnitudes resultan más modestas, lo que puede resultar de interés tanto al estudiar a los escasos efectivos que componían la capilla a inicios del reinado como para comprender la evolución del número de capellanes, que a final del reinado se acercaba a los 120.

Tabla 1. Evolución del número de capellanes y cantores en la Corte de Fernando el Católico. Elaboración propia44

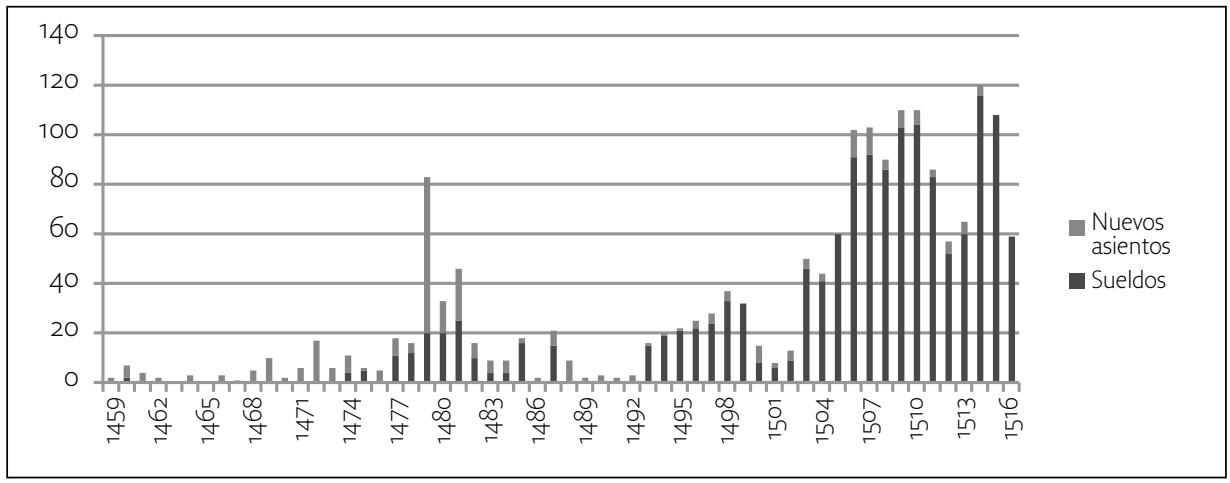

43 La evolución de las prerrogativas del capellán mayor están detalladas en el estudio de David NoGALES RINCÓN, La representación religiosa de la MONARQUÍA... [ver n. 8], pp. 502-509.

44 Para la confección de esta tabla se han empleado los registros de la Escribanía de Ración albergados en el ACA. Para un desglose del número de cantores, junto con un trabajo monográfico sobre los mismos, véase Tess KNIGHTON, Música y Músicos en la Corte de Fernando el Católico (147-1516), Zaragoza, 2001. 
La combinación de todas estas características (la dimensión institucional y representativa de algunos de sus cargos; su papel en la religiosidad cortesana; así como el aumento de sus efectivos) nos conduce a la consideración de este departamento cortesano como un grupo de poder, dentro y fuera de la Corte, y con ello al escenario político que trataremos de desentrañar en las siguientes páginas.

\section{LA CONEXIÓN DE LA CAPILLA REGIA CON LOS GRUPOS Y PROYECTOS FERNANDINOS}

Los análisis de los séquitos medievales se han vehiculado en ocasiones a partir de las palabras de don Juan Manuel y de Alfonso X el Sabio, quienes establecían entre los diferentes oficiales de los séquitos de los poderosos aquellos de dentro de la casa y aquellos de fuera, también denominados «de la tierra». Con responsabilidades diferentes, ambos se daban cita en la Corte como el espacio de gobierno del reino ${ }^{45}$. Sin embargo esa distinción no resulta tan eficaz a medida que nos desplazamos hacia los siglos bajomedievales. Muchos de los oficiales de la tierra desaparecieron con el trascurrir de los siglos mientras que en el caso de los oficiales de la casa puede observarse un progresivo recorrido hacia la politización de su actividad. La Corte, ya sea desde la posición del contador mayor o del repostero, se convirtió en una plataforma para influir en la voluntad del soberano, en la política de los reinos o, al menos, en un espacio para acceder a los mecanismos de la gracia regia ${ }^{46}$.

Analizar la situación de la Corte fernandina en este proceso resulta complejo. A pesar de encontrarnos en las postrimerías del periodo medieval, la dinámica cortesana no había mostrado en ningún momento una direccionalidad. Ni existe una línea continua en el papel político de los cortesanos, ni se observa un predominio de un departamento áulico sobre otro a lo largo de los reinados de los últimos trastámaras. Se trata de un proceso imbricado en los mecanismos de la gracia regia, como muestra, entre otras facetas, del poder del soberano. Para la cronología que nos ocupa, resulta especialmente evidente el papel que la Cámara y la Capilla recibieron en el séquito de la reina Isabel I. Directamente potenciadas por un desarrollo propio de su reginalidad, aparecen como dos plataformas

45 Partida II, Título IX, Ley $1^{\mathrm{a}}$.

46 Sobre una visión de la Corte del rey de Castilla y su evolución a lo largo de la Edad Media Véase Jaime SAlAZAR Y ACHA, La casa del Rey de Castilla y León en la Edad Media, Madrid, 2000. 
de su poder femenino ${ }^{47}$. En el caso de Fernando el Católico esta afirmación se ve tamizada por un aspecto esencial de su herencia aragonesa. Se trata de la búsqueda del equilibrio que gobernase la Corte por encima de la gracia regia sin que pudiera volverse tampoco en su contra, tal y como se infiere de la lectura de las Ordinacions de Pedro IV. Esta es una de las principales características que definen el séquito de Fernando II, y en especial conforme más nos alejamos de su infancia (es decir, conforme va aumentando su poder y se transforma de un entorno meramente personal a un grupo político). Así, a lo largo del reinado se observa una evolución contradictoria: mientras que los oficios tradicionales comienzan a desdibujarse, éstos lo hacen bajo las directrices del mantenimiento del equilibrio de poder en el seno de la Corte ${ }^{48}$.

\section{III.1. Los límites del servicio religioso}

Esta dinámica general en el caso de la Capilla se materializó en la constitución de un cuerpo religioso fuertemente volcado en sí mismo. Dicha característica, que no minó su influencia política, sí le concedió determinadas características dentro de la sociedad cortesana. Así, y al menos para una primera cronología que llegaría hasta la muerte de la reina Isabel, la Capilla se convirtió, como venimos defendiendo, en un espacio a modo de receptáculo de las grandes élites del momento aunque, como en todo hecho histórico, con sus matices. No puede dudarse que el entorno religioso del monarca supuso un foco de atracción para las élites de todos los reinos bajo su dominio de una manera constante durante su gobierno. Sin embargo en los difíciles inicios del reinado hablaríamos de los familiares de los grandes cortesanos vinculados al rey. Es el caso, por ejemplo, de los familiares de los Santángel y los Sánchez (gestores económicos, algunos de ellos nombrados incluso por Juan II) ${ }^{49}$, de aquellos cercanos al secretario Villasimpliz (que llegará a ser secretario del emperador) ${ }^{50}$, o de colaboradores como el ya mencionado Alcaraz, Sesé ${ }^{51}$, o ya, más tardíamente, Albión (gran diplomático

47 Parte de la extensa bibliografía sobre el entorno de la Reina Católica en la que se trata con mucho más detenimiento esta cuestión está recogida en la nota 7.

48 Sobre la evolución de las redes internas dentro de la Corte de Fernando II, Germán GAMERO IGEA, Ordenar la Corte y gobernar los territorios [ver n. 17].

49 ACA.RP.MR., vol. 920, fol. 82v; ibid., fols. 22r, 36v y vol. 939, fol. 125v, respectivamente.

50 Ibid., vol. 922, fol. 4r.

51 Ibid., vol. 939, fol. 55r. 
fernandino) ${ }^{52}$, Ariño (de nuevo, secretario, en este caso desde 1474) ${ }^{53}$ y Agostí (quienes llegarían a ser vicecancilleres) ${ }^{54}$. Se trata por tanto de una manera de diversificar la influencia de los grandes cortesanos por medio de su extensión en las redes internas dentro de la Corte pero que no sobrepasa el ámbito cortesano. Dicho proceso debe encuadrarse en el contexto político más amplio de formación e inestabilidad del propio partido fernandino que poco a poco fue modificándose. Poco a poco en todos los ámbitos de la Corte observamos una visión más envolvente y política, al asumir nuevos integrantes que ostentaban un importante peso en la toma de decisiones en las instituciones de los reinos.

Precisamente esos últimos apellidos nos permiten transitar hacia ese segundo momento en el que destacan algunas de las grandes casas nobiliarias, especialmente a partir del cambio de siglo. Se trata, no lo olvidemos, de un momento de consolidación de la figura del soberano en el tablero político, pero también de pérdida de iniciativa de la reina Isabel I y del ascenso de la influencia de quien se juraba como príncipe: Felipe el hermoso. Como nuevos integrantes de la capilla destacan, por ejemplo, los Requesens de Soler, gobernadores en Cataluña. Alejados de la Corte pero cercanos a las instituciones de gobierno, vuelven a vincularse al entorno regio por medio de Juan (probablemente hijo de Luis, hermano de Galcerán) y Luis de Requesens, capellanes activos en el séquito a partir del cambio de siglo ${ }^{55}$. De manera semejante podría destacarse la familia Cardona (que, no lo olvidemos, había llegado a entroncar con la familia real), para la que don Jaime, hijo del conde, aparece como representante en el bienio 1496-149756. Incluso familias como los Ferrer (importantes nobles valencianos que llegaron a controlar el séquito de la reina Juana I en su reclusión en Tordesillas) aparecen en la Capilla del rey desde 150957, así como los Vilanova y los Centelles, algo más tardíamente, desde $1511^{58}$. También los naturales de la corona de Castilla intensificaron su presencia en la Capilla regia por esas fechas. Para este caso podrían destacarse agentes como Juan de Vega, hijo del poderoso Fernando Vega (señor de Grajal de Campos e importantísimo consejero de Fernando II gracias entre otros motivos a su conexión con el Duque de Alba), o don Pedro de Peralta, vástago de conde de Santisteban ${ }^{59}$.

52 Ibid., vol. 920 , fol. $218 \mathrm{v}$.

53 Ibid., vol. 939, fol. 56v.

54 Ibid., vol. 922, fol. 19r.

55 Ibid., vol. 920, fol. $166 \mathrm{v}$ y $158 \mathrm{r}$ respectivamente.

56 Ibid., vol. 841, fol. 18 r.

57 Ibid., vol. 922, fol. 8v.

58 Ibid., vol. 957 , fol. $143 \mathrm{v}$ y vol. 847 , fol. 191v, respectivamente.

59 Ibid., vol. 920, fol. 171r y vol. 922, fol. 24v. 
No obstante dentro del solar castellano merece la pena destacar una situación particular: la incorporación de los capellanes que procedían del séquito de su mujer. Como es posible observar en la Tabla 1 hay una clara correspondencia entre la muerte de la reina y el aumento (casi duplicación de efectivos) de la Capi1la. Dicha evolución resulta interesante sobre todo por confirmar la importancia de la vinculación de las élites eclesiásticas con las capillas reales. Pero este proceso es matizable en cuanto a la correspondencia de los oficiales, algo cuanto menos sorprendente ante la comunión de intereses por parte de la pareja regia. Efectivamente, y a pesar de la sobredimensión, el número de los capellanes isabelinos asumidos por el soberano resulta escaso y, sobre todo, no superan la prueba del viaje napolitano de Fernando $\mathrm{II}^{60}$. Son ejemplo de ello Juan Texén, Pedro Ruiz de la Mota, predicador, o Francisco de Milán hijo del licenciado de Guadalupe ${ }^{61}$. Ninguno de ellos tendría una trayectoria representativa al servicio del Rey Católico. Mucho más interesante resulta si contrastamos este hecho con el destino de los músicos. En esta ocasión sí puede hablarse de una continuidad entre un séquito y otro. Se trata de recorridos como el de Bartolomé de Aguilera o Bernardino de Baena, y de otros con tanto relieve para la historia de la música como el propio Juan de Anchieta ${ }^{62}$. Este trasvase de músicos no es excepcional para estas fechas y resulta conveniente destacar que la misma reina Juana a la muerte de su marido demostró un comportamiento semejante pues siente gran deleite en las melodías musicales, arte que ella aprendió en su tierna infancia ${ }^{63}$. En cualquier caso lo que sí evidencia esta incorporación al séquito del Rey Católico de oficiales propios de la reina es su carácter de escasa relevancia política y su función doméstica. Resulta evidente que el soberano conocía los recursos musicales de la Capilla de su consorte y la intensidad a la que debió estar sometida la colaboración de los dos entornos regios fue muy intensa ${ }^{64}$. Esta hipótesis podría reforzarse si se tiene

60 Para su comparación, y a falta de un estudio sistemático sobre la prosopografía de este grupo áulico para la capilla de la reina se han empleado los volúmenes editados de la casa de la reina y de la tesorería de Isabel I como una aproximación a las últimas nóminas de la soberana. Véase Antonio DE LA TORRE Y DEL CERRO, La Casa de Isabel... [ver n. 6]; Rosana DE ANDRÉs DÍAZ, El último decenio del reinado de Isabel I a través de la tesorería de Alonso de Morales (1495-1504), Valladolid, 2004.

61 Antonio DE LA TORRE Y DEL CERRO, La Casa de Isabel... [ver n. 6], p. 141, ACA.RP.Mr. vol. 920, fol. 212v; Antonio DE LA TORRE Y DEL CERRO, La Casa de Isabel... [ver n. 6], p. 142, ACA. RP.MR. vol. 843, fol. 191v; Antonio DE LA TORRE Y DEL CERRO, La Casa de Isabel... [ver n. 6], p. 186, ACA.RP.MR. vol. 844 , fol. 22 v.

62 El primer asiento de Anchieta data del 15 de abril de 1512. ACA.RP.MR. vol. 922, fol. 22v.

63 Pedro Mártir DE ANGlería, Epistolario, trad. por José LóPEZ DE Toro, Madrid, 1955, vol. 2, p. 154.

64 Esta relación ya fue señalada por Tess Knighton, Música y Músicos... [ver n. 44]. 
en cuenta que puede darse noticia de algunas conexiones ya antes de la muerte de la reina como sucede en el caso de Bernardino de Vozmediano, que aparece percibiendo quitaciones por las dos capillas ${ }^{65}$.

Un aspecto relacionado con esta disparidad de efectivos lo encontramos en el seno de la propia Capilla de Fernando II y el peso que él había concedido a algunos de sus colaboradores con más trayectoria de servicio. Como ya hemos comentado en el apartado precedente, no debería perderse de vista el carácter reducido de la Capilla fernandina al inicio de su reinado. Durante gran parte de su gobierno este grupo se caracterizó por ser un núcleo estable y reducido. Tanto es así que podría hacerse una distinción entre la estabilidad de los «capellanes y cantores», encargados de atender al culto regio, y el grupo de los «capellanes», mucho menos estable en la duración del servicio y por tanto presentes en un número más elevado. Bien es cierto que pueden destacarse diferentes excepciones. Entre otros capellanes, que posteriormente tendremos ocasión de mencionar, podría destacarse a Jaime de Urriés, que se encontraba familiar y tradicionalmente relacionado con la Corte de Fernando, le encontramos al menos entre 1491 y 1510 al frente del servicio regio ${ }^{66}$. Por otro lado Juan de Salazar muestra un servicio desde 1494 hasta final del reinado ${ }^{67}$. Sin embargo ninguna hoja de servicio puede compararse con la de Alonso Cortés, protonotario apostólico. Sabemos que se vinculó con el servicio desde su más tierna infancia, como escolán de capilla, en $1470^{68}$. A partir de ese momento su vida estaría íntimamente ligada a la Capilla regia, en donde llegará a ser sacristán mayor y a desarrollar la camarilla y posición de dominio ya comentada. Más allá de estos nombres deberíamos por último referirnos a todos aquellos que en el siglo XVI hacen gala de ofrecer sus servicios en la Corte. Se trataría de un nuevo cuerpo político de capellanes, con nuevas características y que incluso aportan una nueva dimensión a la capilla, mucho más vinculado con la política. Es el caso de Rodrigo Sánchez de Mercado, Bernat Almogávar, Felipe Pons, Juan de Zurita y Alfaro, Juan de Loaysa, Francisco de Mendoza, Artal de Bolonia, Francisco Juan de Lorach y un largo etcétera, quienes dan pie a consideraciones diferentes sobre el servicio regio.

65 La primera quitación registrada para Bernardino de Vozmediano, como mozo de capilla es de 1 de octubre de 1494 (ACA.RP.MR. vol. 840, fol. 135r).

66 Estas fechas extremas están recogidas en ACA.MR. vol. 920, fol. 125r, e ibid., vol. 846, fol. 251r.

67 Su primer y último asiento se encuentran en ACA.RP.Mr. vol. 840, fol. 111r, e ibid., vol. 847, fol. $234 \mathrm{r}$

68 ACA.RP.MR. vol. 939, fol. 68r 
Antes de llegar a ese punto convendría subrayar el hecho de que en ningún caso esto implicó una preeminencia en las redes internas cortesanas ${ }^{69}$. Independientemente de que la confianza que depositase el soberano, resulta altamente infrecuente que personajes forjados en la Capilla extendiesen su influencia más allá de su departamento, especialmente durante el periodo menos politizado, como observaremos. Véase por ejemplo el caso de Alonso Cortés, cuyos familiares se mantienen dentro de los muros del servicio religioso. Sin embargo, los cambios que venimos reseñando sí que tuvieron una clara influencia en la proyección de la Capilla fuera de la Corte, de manera lógica y pareja a la propia permeabilidad de la misma a los quehaceres del reino.

\section{III.2. Más allá de palacio}

Frente a este proceso de contención interna que se viene detallando podemos observar una cara menos restrictiva de la moneda. En ella se nos muestra el valor concedido por el Rey Católico a sus colaboradores. Bien es cierto que ya en los propios salarios podemos apreciar una mayor valoración de la Corte del rey que por parte de Isabel la Católica ${ }^{70}$. Pero más allá de sus quitaciones es en el uso de la gracia regia donde mejor podemos ver el apego por parte del rey hacia sus capellanes. Base del sistema de Corte, la gracia regia adquiere en este reinado algunos aspectos peculiares, al menos desde dos puntos de vista: los beneficios económicos a modo de rentas y, por otro lado, el aumento de su responsabilidad en la gestión de asuntos políticos.

69 Este rasgo es compartido con el resto de integrantes del clero salvando la excepción de cardenal Margarit, vinculado a la Cancillería y no a la Capilla, y en menor medida, con Sánchez de Mercado, como tendremos ocasión de destacar El Obispo de Elna es un buen ejemplo la reincorporación de la nobleza catalana (ya que habían sido consejeros de los últimos monarcas del casal de Barcelona), en el entorno regio. Es muy conocida su participación en la guerra civil catalana, pero también debe recordarse que gracias a esa influencia consiguió incorporar a otros miembros de su familia en la corte. El más importante y que más continuidad tuvo en la Corte de Fernando fue Luis Margarit, con el cargo de Camarlengo desde 1478, hasta, por lo menos el 98, y luego asciende a gentilhombre de la casa en 1512, por lo que su trayectoria parece asegurada. El segundo de ellos es el hermano de Luis, Pedro Margarit, al que vemos como contino y como hombre de armas en la Guerra de Granada, lo que le supondrá pingües beneficios, ya que en el segundo de los viajes de Colón aparece como representante del monarca.

70 La quitación más habitual en la Capilla de la reina es de 8.000 mrs (Antonio DE LA TORRE Y DEL CERro, La Casa de Isabel... [ver n. 6] mientras que en el caso de Fernando II esa cifra puede duplicarse o incluso triplicarse, lo que permite explicar también la diferencia comparativa entre una capilla y otra. 
Por lo que respecta a la cuestión pecuniaria merece destacarse el insistente recurso al indulto papal con el que dotar a los capellanes de las rentas correspondientes a su estatus. Así pues Fernando II activó los resortes de la diplomacia pontificia hasta en cinco ocasiones, una por cada pontificado $(1483,1485$, 1494 , otro en una fecha imprecisa, en torno a 1503, y 1513) ${ }^{71}$. No quiere decir esto que no encontrase en ello importantes dificultades, como las registradas con el Papa Inocencio VIII entre 1484 y $1487^{72}$, o en el tenso pontificado de Alejandro $\mathrm{VI}^{73}$. Sin embargo su sistematicidad parece innegable. La estructura de todos los indultos resulta semejante, destacando la cláusula de prelación de los oficios nombrados por el rey sin excepción, incluso para aquellos beneficios reservados a los clérigos in curia (incluidos los cardenales) como consecuencia de las constantes pugnas que se producían por su disfrute. Así, las mayores variaciones las encontramos en la cuantía (que llegará a los 5.000 ducados, en 1503) o los reinos sobre los que se estos indultos debían recaer, ya sea aquellos de la Corona de Aragón, o Nápoles como reino independiente. Otra vía de mejorar la posición de la Capilla regia la observamos en la inusual incorporación de beneficios (en comandita) a título institucional, como reclama Fernando el Católico a Sixto IV en 1483. Por una misiva al papa sabemos que el soberano requirió al pontífice se concedieran 150.000 mrs. de renta de los 300.000 que Juan de Ayllón poseía en vida sin saber si finalmente se concedieron dichas rentas $^{74}$.

En estas formas de petición colectiva de mercedes sólo podemos intuir la libertad del soberano en distribuirlas y la autoridad del capellán mayor como juez en la disputa de las prebendas dentro de la Corte ${ }^{75}$. No obstante frente a ellas destacan las peticiones de beneficios individuales que por medio de la cancillería regia llegaban hasta la curia papal. Si es un mecanismo que contaba con una larga tradición en las relaciones hispano-romanas, pueden destacarse algunas peculiaridades en el caso del Rey Católico. En primer lugar la correspondencia entre el histórico grupo de capellanes con aquellos más beneficiados

71 La mayor parte de ellos se encuentran en RAH. Colección Salazar y Castro, vol. K-6, o en Antonio DE LA TORRE (dir), Documentos sobre las relaciones internacionales... [ver n. 38].

72 Antonio DE LA TORRE (dir.), Documentos sobre las relaciones internacionales... [ver n. 38], vol. 2, pp. 412-414.

73 Ibid., vol. 3, p. 435.

74 Ibid., vol. 1, p. 329.

75 Sobre la autoridad de este oficial en las disputas de los capellanes y la autoridad delegada del papa a este respecto conviene ver los documentos pontificios recogidos en Bulas y breves pontificios... [ver n. 36]. 
por el soberano ante el papa. Se repiten nombres como Alonso Cortés ${ }^{76}$, Juan Ortega $^{77}$, o Jaime de Urriés ${ }^{78}$. Pero también aquellos mejor posicionados en los grupos de presión vieron recompensada su posición ventajosa. Es el caso del sobrino del tesorero, Gaspar Sánchez, que será también un gestor económico importante en el reino de Aragón al asumir, junto con otros religiosos, la testamentaría de Juan de Aragón, que fuera arzobispo de Zaragoza ${ }^{79}$. También el sobrino de Juan Coloma se beneficiaría de esa posición ventajosa al igual que el hermano del vicecanciller, Pablo de la Cavallería, que llegaría a ser nombrado obispo de Cefalú en $1495^{80}$. El resto de capellanes no desaparecen de estas relaciones, si bien sus posiciones resultan mucho más modestas en las mercedes otorgadas (pequeñas raciones en catedrales, permutas con oficiales romanos, defensa ante reclamaciones externas, etc. ${ }^{81}$ ). Aunque no se limite a ellos, bien es cierto que con los clérigos cercanos al entorno regio el patronato, más allá de considerarse una prerrogativa necesaria para la reforma y la independencia de la Iglesia hispana, aparece como una manera de construir el poder regio en especial en lo referente a la gracia.

Sin embargo no sería la única manera de extender el poder de los principales colaboradores del soberano. Fernando II, desde una posición más comedida que la de su mujer, quien permitió el ascenso de grandes consejeros como Hernando de Talavera, el cardenal Mendoza o Francisco Jiménez de Cisneros, gestionó también el capital simbólico que sus capellanes le reportaban, pudiendo diferenciarse al menos dos etapas. En la etapa que venimos defendiendo como menos politizada nos encontramos con que los principales colaboradores del Rey Católico son, precisamente aquellos que gozaban por derecho propio de una gran autoridad: Pedro de Mendoza y Juan Payo Cuello. Siendo ambos de origen castellano, no sólo presidieron la Generalitat en momentos intermitentes ${ }^{82}$, también defendieron la posición fernandina en diferentes asuntos religiosos. Uno de ellos fue el control de la reforma de las órdenes. Así, el abad de Poblet aparecerá como

76 Antonio DE LA TORRE (dir.), Documentos sobre las relaciones internacionales... [ver n. 38], vol. 4, p. 555 ; vol. 5 , pp. $358-359$.

77 Ibid., vol. 2, pp. 60-61.

78 Ibid., vol. 4, pp. 198, 240, 452-453.

79 Ibid., vol. 1, p. 102.

80 Ibid., vol. 5, p. 23.

81 Ibid., vol. 1, pp. 93, 122, 280-281; vol. 2, pp. 21-22, 24-25, 76-77, 84, 170-171; vol. 3, pp. 316317, 387-288; vol. 4, pp. 281, 493-494, 519, 523; vol. 5, pp. 175, 335-336, 353-355, 501-502, vol. 6. p. 174.

82 Josep María SolÉ I SABATÉ, História de la Generalitat... [ver n. 25] pp. 226-229; 247-252. 
el reformador de toda la orden del Císter en los reinos de España ${ }^{83}$. Mientras, Pedro de Mendoza aparece de manera intermitente en este proceso, como se observa en su visita al monasterio de Valldigna para obseruacio de les ordinacions e constitucions antigues $^{84}$. De esta última colaboración cabe destacar no sólo la dimensión religiosa, sino también la política al situarse en un momento complejo en el que la familia Borja había iniciado sus primeras tentativas para incorporar el cenobio a su patrimonio ${ }^{85}$.

También podrían destacarse algunos de los capellanes que habían gozado de la confianza regia y habrían prolongado su servicio en la Corte, pues habrían sido recompensados con el desarrollo de una importante carrera política. Es el caso de Juan de Ortega, quien fue provisor de Villafranca y sacristán mayor de Fernando II al menos entre 1469 y $1484^{86}$ y eminente organizador de la Hermandad General. También Sancho de Londoño, presente desde 1479, aparece en los registros hasta la muerte del soberano y ocupó ciertos puestos de responsabilidad como la embajada extraordinaria a Inglaterra en $1498^{87}$. Sin embargo se trata de quehaceres poco relacionados con asuntos religiosos y creemos que es más fácil vincular estas trayectorias de servicio más a la convivencia con el rey que a su caracterización como clérigos.

Para indagar en esa conexión entre política y religión, como habían demostrado Pedro de Mendoza y Juan Payo Cuello, deberíamos referirnos, de manera ineludible, al establecimiento del tribunal del Santo Oficio, uno de los aspectos, además, en donde mejor puede observarse la politización de la capilla palatina. Todavía en un primer momento puede observase cómo los inquisidores no parecen nutrirse de, ni vincularse con (lo que resulta más significativo) la Capilla real ${ }^{88}$. Los

83 Antonio DE LA TORRE (dir.), Documentos sobre las relaciones internacionales... [ver n. 38], vol. 1, p. 170.

84 Ibid., vol. 2, p. 403.

85 Ibid., vol. 2, pp. 402-403.

86 La primera ocasión en el que se le inscribe como sacristán mayor puede fecharse en Zaragoza, el 21X-1469 (ACA.RP.Mr., vol. 939, fol. 61v), la última referencia que conocemos se encuentra en Antonio DE LA TORRE (dir.), Documentos sobre las relaciones internacionales... [ver n. 38], vol. 2, pp. 60-61.

$87 \mathrm{El}$ primer asiento de este oficial se corresponde con el registro ACA.RP.MR., vol. 840, fol. 113r; el último con ibid., vol. 847 , fol. $235 \mathrm{v}$.

88 No hemos logrado encontrar una vinculación con la capilla por parte de Juan Orts ni de Gualbes, Pedro de Arbués, Jutglar o Caselles los inquisidores más representativos en la Corona de Aragón en su primera etapa, ni tampoco por parte de Miguel de Morillo o Juan de San Martín (primeros inquisidores en Sevilla) ni ninguno de los propuestos por documento pontificio de 1482 para Castilla. Aunque el estudio prospográfico del entorno de la reina no es completo, tampoco lo hemos encontrado entre sus servidores. No se trata, al menos hasta la muerte de Torquemada (con la incorporación de Deza, Cisneros y nuevos aparatos de gobernador de la inquisición) de clérigos que hubiesen crecido a la sombra de la Corona. 
ejemplos que contradicen esta tónica general son muy escasos y en ocasiones su vinculación con el séquito regio es más que dudosa. Así, Juan Crespo, un capellán asentado de manera honorífica antes de 1488, parece haber estado relacionado con la Inquisición antes del gobierno en solitario de Fernando ${ }^{89}$. Para el caso de Martín García, inquisidor en Zaragoza en 1490, resulta interesante que las fuentes le denominen como capellán del rey, pues no hemos logrado encontrar registro de quitación o certificación de oficio. Lo mismo ocurre con Diego Pérez inquisidor en Toledo, de quien se dice que es capellán regio en $1488^{90}$. Ya por último, resulta distinta la posición de Juan de Monesterio. Natural de Burgos y perteneciente a la Capilla, pero de la reina, ejercería sus labores inquisitoriales en Valencia en $1493^{91}$.

Si estas referencias pudieran resultar numerosas, poco probable ante la extensión de diferentes tribunales provinciales, tendríamos que tener en cuenta que todas ellas hacen mención a un periodo en el que la Inquisición ya había dado sus primeros y fructíferos pasos. Para fechas anteriores no serían capellanes, sino otros cortesanos, los que aparecen como colaboradores del rey. Así por ejemplo la participación de los secretarios Camany[ñ]as y Juan Ruiz de Calcena en el establecimiento del tribunal turolense está lejos de cualquier duda ${ }^{92}$. Pero también podríamos encontrar otras figuras más modestas pero igualmente fundamentales en esos críticos momentos. Se trata por ejemplo de Ruiz Sánchez de Zuazu, procurador fiscal de la inquisición de Zaragoza y que había sido capellán de Fernan$\mathrm{do}^{93}$, o Alfonso de Mesa y Juan de Medina, receptores en Teruel que ya se vinculaban a la Corte desde tiempo atrás con el cargo de contino ${ }^{94}$. El mismo cargo lo asume Amador de Aliaga, proveniente del poderoso clan de los Sesé y quien se convertiría en uno de los principales gestores económicos de la Inquisición en sus primeros $\operatorname{pasos}^{95}$.

Para encontrar un aumento de la nómina de cortesanos implicados en las tareas inquisitoriales, y especialmente en el caso de los religiosos, deberíamos espe-

89 ACA.RP.MR. vol. 920, fol. 115 r.

90 Antonio DE LA TORRE (dir.), Documentos sobre las relaciones internacionales... [ver n. 38], vol. 3, p. 160.

91 Antonio DE LA TORRE Y Del Cerro, La Casa de Isabel... [ver n. 6], p. 29.

92 Sobre la participación de estos secretarios véase José Ángel SESMA MUÑOZ, El establecimiento de la Inquisición en Aragón (1484-1486): documentos para su estudio, Zaragoza, Institución Fernando el Católico, 1987.

93 ACA.RP.MR. vol. 939, fol. 152r.

$94 \mathrm{El}$ asiento de Alonso de Mesa se registra en ibid., fol. 28r y el de Juan de Medina en ibid., fol. 30v.

95 Su asiento como hombre de pie, que le vincula con Manuel Sesé se encuentra en ACA. RP.MR. vol. 939, fol. 154r. 
rar a los profundos cambios producidos durante la segunda regencia fernandina. Así, nos encontraríamos con casos como los de Miguel de Icart, Juan de Loaysa o Gaspar Pou, inquisidores todos ellos que se vinculan con el departamento religioso del soberano. Sin embargo para el periodo de mayor esplendor del régimen fernandino destaca la vinculación de Rodrigo Sánchez de Mercado con la Capilla real. Este oficial, mucho más famoso por su labor inquisitorial que por su vinculación cortesana con el Rey Católico, aparece como capellán desde $1502^{96}$. Si ya sólo su figura es destacable en el contexto hispano, lo es también que su absoluta preeminencia en la administración inquisitorial se tradujo en uno de los pocos casos de extensión de la influencia por la Corte. Se trata de Juan de Otalora, mozo del bacín del soberano y por tanto una de las personas capaces de acceder al ámbito más secreto del rey, de quien se dice que era criado del inquisidor ${ }^{97}$.

Tanto la vinculación de los inquisidores con la Capilla como su capacidad de influencia en un ámbito tan cercano al rey muestran una vez más cómo los nuevos aires del reinado traían al séquito regio nuevas características y realizaciones. Una de las más importantes fue un nuevo matiz en la vinculación institucional de la Capilla con la política religiosa del momento, que se hace más estrecha a medida que avanza el reinado. Aparece por tanto una dimensión del espacio cortesano más influido por la religiosidad que, no en balde, conducirá la formación de los partidos en los reinados de Carlos V y Felipe II, ya con nuevas directrices, nuevos retos, nuevas personas, y en definitiva, nuevas concreciones basadas en un escenario heredado, complejo y mutable.

\section{CONCLUSiOnes}

Sin dudar del carácter personal que habitualmente se atribuye a las capillas regias de los soberanos bajomedievales, puede observarse cómo el departamento religioso del Rey Católico se mostró especialmente sensible a los cambios políticos del reinado, cambiando su naturaleza hacia posiciones más relacionadas con la política, y en especial con la política religiosa.

A pesar de no encontrar una línea directriz, sino una sucesión de respuestas ante los problemas políticos que se fueron planteando, sí podemos encontrar algunas causas que convirtieron a la Capilla del Rey Católico en terreno abonado

96 ACA.RP.MR. vol. 843, fol. 194v.

97 La primera ocasión en la que aparece la relación entre ambos es en un asiento del propio inquisidor, con fecha 15 de julio de 1507 (ACA.RP.MR. vol. 844, fol. 246r). 
para este proceso. En primer lugar, la permanencia de algunas de las vinculaciones tradicionales entre la capilla y algunas de las grandes instituciones de sus reinos que conservaban un importante capital simbólico. También resulta significativo el proceso por el cual desde la monarquía, y gracias al papel de las bulas pontificias, se logró una mayor valoración en términos religiosos de los capellanes, quienes incluso extendieron su influencia hacia la vida de los cortesanos, ya sea por medio de la cura de almas o por el establecimiento de instituciones novedosas o al menos renovadoras como la cofradía de Corte. Un tercer mecanismo que puede constatarse a este respecto para el reinado de Fernando II fue la vinculación de las grandes familias (ya sea cortesanas o de la nobleza) con la Capilla. Incluso, el desarrollo de la gracia regia, ya iniciado en reinados anteriores, encontrará bajo el reinado de Fernando II un momento de especial relevancia, siendo conjugada con la defensa del patronato regio. A medio camino entre causas y consecuencias, el aumento de efectivos y la colaboración con el séquito de la reina Isabel I, ayudan a dibujar la panorámica que permitiría que el peso político de la Capilla fuese aumentando de manera progresiva y se insertara en las diferentes redes cortesanas.

Gracias a todo ello el estudio del aparato religioso, puede ser un escenario de estudio muy representativo de la vida cortesana sin que las perspectivas de análisis se agoten en este trabajo. Resulta interesante su calidad de escenario de la pulsión entre innovación y tradición, de la vigencia, encubierta, del orden aragonés en la Corte del soberano, de las relaciones en el régimen dual de los Reyes Católicos o de los profundos cambios que fueron sucediéndose en los séquitos de los soberanos a la hora de configurar un nuevo régimen, dinámico y eficaz respecto a sus metas políticas. 